\title{
Signs and Docents in Zoo Visitor Education: Using Affinitive Chimpanzee (Pan troglodytes) Behaviors
}

\author{
Lindsay N. Zager ${ }^{1}$ and Mary Lee A. Jensvold ${ }^{1,2, *}$
}

${ }^{1}$ Friends of Washoe, Ellensburg, WA

${ }^{2}$ Primate Behavior \& Ecology Program, Central Washington University

*Corresponding author (Email: jensvold@ faunafoundation.org)

Citation - Zager, L. N., \& Jensvold, M. L. A. (2021). Signs and docents in zoo visitor education: Using affinitive chimpanzee (Pan troglodytes) behaviors. Animal Behavior and Cognition, 8(4), 589-600. https://doi.org/10.26451/abc.08.04.10.2021

\begin{abstract}
The goals of zoos are providing an entertaining and educational experience for visitors, promoting environmental conservation, and promoting positive welfare for nonhuman residents. Education can unify these goals. In this study, data were collected on visitors to the chimpanzee (Pan troglodytes) exhibit at The Zoo Northwest Florida. Researchers implemented three conditions of education at the chimpanzee viewing platform: a graphic sign, a trained docent, and a control condition with no intervention. The sign and docent encouraged visitors to use affinitive chimpanzee behaviors. Visitors were significantly more active in the graphic sign condition and significantly less active in the docent condition, and their behavior did not vary from the expected value during the control condition. Visitors used the affinitive behaviors that were demonstrated in each experimental condition. These results suggest that both graphic signs and docent interaction affect visitor behavior and can be considered useful educational tools for fulfilling the goals of the zoos.
\end{abstract}

Keywords - Zoo, Visitor behavior, Visitor education, Species-specific behavior, Animal visitor interaction, Visitor effect

The goals of zoos are providing an entertaining experience for visitors, educating visitors and the surrounding community, promoting environmental conservation, and providing positive welfare for nonhuman residents (Ballantyne \& Packer, 2016; Carr \& Cohen, 2011; D’Cruze et al., 2019; Godinez \& Fernandez, 2019; Hutchins \& Smith, 2003; Lindemann-Matthies \& Kamer, 2005; Milan \& Wourms, 1993). Zoos provide education on the behavior and conservation of the species within their collections (Milan \& Wourms, 1993; Rabb, 2004; Stoinski et al., 2001) using varying media within animal exhibits as well as through additional programs that occur before, during, or after a zoo visit (Fernandez et al., 2009; Mench \& Kreger, 1995; Milan \& Wourms, 1993; Ross \& Gillespie, 2009; Ross \& Lukas, 2005; Smith et al., 2008), including interactions such as feeding, petting, riding, shows, or swimming (D'Cruze et al., 2019). Whereas in the past, zoos' goals may have been mutually exclusive, the advent of environmental enrichment, interactive visitor interpretive programs, and naturalistic exhibits have made the fulfillment of these goals possible. Education can serve as a means of unifying zoo goals; educated and engaged visitors can perhaps contribute to animal welfare by following instructions on how to engage in species-specific behavior that can decrease stress on animal residents (Birke, 2002; Boyle et al., 2020; Lee, 2015; Rabb, 2004).

The effect of visitors on zoo-living primates can be positive, negative, or neutral (see Sherwen \& Hemsworth, 2019 for review; Carder \& Semple, 2008; Chamove et al., 1988; Claxton, 2011; Davey, 
2007; Kuhar, 2008; Mallapur et al., 2005; Stoinski et al., 2012; Wells, 2005). Zoo visitors want to interact with zoo-living apes (Kreger \& Mench, 1995; Wood, 1998), yet in doing so, sometimes unknowingly engage in threatening behaviors (Mitchell et al., 1992). In an attempt to interact, for example, human visitors sometimes imitate the behaviors they see such as vocalization (Cook \& Hosey, 1995) and hostile behaviors (Nimon \& Dalziel, 1992). Apes sometimes respond to this imitation and the interaction can escalate, causing heightened aggression and increased stress (Hosey \& Melfi, 2015; Osvath, 2009). However, when visitors to several monkey exhibits adopted a species-specific crouched posture, the monkeys responded with an increase in grooming behavior and a decrease in inactivity (Chamove et al., 1988). Similarly, caregivers' use of friendly behaviors decreased aggression and increased affiliation in a group of zoo-living chimpanzees (Jensvold, 2008), suggesting that humans' use of affinitive behaviors does impact chimpanzee behavior. The use of affinitive behaviors by zoo visitors can serve to mitigate some of the stress of visitors, promoting the welfare mission of zoos.

Zoos have a variety of ways of informing their visitors (Altman, 1998). The most common educational medium is graphic signs. Graphics, illustrations, and color in an exhibit sign can increase visitor interest and prolong the time visitors spend at a particular exhibit (Bitgood et al., 1986; Coe, 1992; Foster et al., 1988). Another medium to inform the public is to facilitate interactions between the visitors and zoo residents (D'Cruze et al, 2019; Kreger \& Mench, 1995). Educational programs featuring live animal interaction increases viewing time and the American Zoological Association encourages the use of live animal demonstrations for education (AZA, 2008). Most recently, technology provides opportunity for interactions between visitors and residents including touch screens, Kinect (Webber, Carter, Smith et al., 2017; Webber, Carter, Sherwen et al., 2017), and virtual reality (Carter et al., 2020).

In a survey of visitors to a large-bodied ape exhibit at the Lincoln Park Zoo, visitors reported that interactions with zoo staff were the most interesting means of education (Gold \& Beneviste, 1995). An exhibit at a Swiss zoo featured a zoo staff member who answered visitor questions and encouraged visitors to participate in hands-on activities; visitors' improved performance on a post-visit test suggested the ensuing dialogue was a successful means of facilitating visitor learning (Lindemann-Matthies \& Kamer, 2005). Similarly, either video presentation or live presentation by zoo staff member increased visitor time spent at an orangutan exhibit and increased visitors' knowledge about orangutans (Perdue et al., 2012).

To educate visitors, zoo staff must understand what motivates visitor attendance. Most zoo visitors are motivated to seek out informal learning opportunities, which can incorporate interaction with humans and nonhuman residents (Ballantyne \& Packer, 2016; Birney, 1988; Bitgood et al., 1986; Falk et al., 2007; Morgan \& Hodgkinson, 1999; Reade \& Waran, 1996). Visitors also wish to experience the natural world and do so by seeking out active animals engaged in animated, non-stereotypic behavior (Altman, 1998; Bitgood et al., 1986; Luebke et al., 2016; Patterson \& Bitgood, 1988). Both social events and natural experiences are opportunities for visitor learning. In this way, the educational goals of zoos and the motivations of visitors can work together (Gold \& Beneviste, 1995; Lindemann-Matthies \& Kamer, 2005; Ross \& Gillespie, 2009).

Understanding how zoo visitors behave is a way to design effective educational programs (Davey, 2007 for review). Only about half of the visitors at an exhibit actively attend to the animals (Foster et al., 1988). Overall visitors' time at an exhibit is short; on average 12 s to 2 min (Bitgood et al., 1986). Various factors can increase viewing time, such as increased animal activity (Altman, 1998; Margulis et al., 2003). Most visitors spend their time engaged in passive observation of animal residents (Davey, 2006), though some visitors engage in negative behaviors such as throwing objects or imitating aggressive behaviors of nonhuman animals (Birney, 1988; Davey, 2006).

While research has shown trends in zoo visitor behavior, little is known about how visitors change their behavior at animal exhibits when presented with a specific intervention. Kratochvil and Schwammer (1997) successfully used signs to encourage a decrease in tapping behavior in aquarium visitors, suggesting that the use of signs may be an effective means of changing visitor behavior. Dancer and Burn (2019) found signs reduced visitor noise levels at a macaque exhibit. Bitgood et al. (1988) found visitors were more responsive to signs with more explanation than signs with simply instructions. 
In contrast, Chiew et al. (2019) found signage had no effect on visitor behavior near little penguins. Altered visitor behavior can be a means to increase positive interactions between visitors and zoo-living animals.

The current study integrates the goals of zoos and expectations of visitors to promote immediate behavioral changes in visitors to a chimpanzee (Pan troglodytes) exhibit. This study implemented two conditions of visitor education: a graphic sign depicting specific affinitive chimpanzee behaviors and a trained docent encouraging visitors to use specific affinitive chimpanzee behaviors. We hypothesized that visitors would be more active and use suggested behaviors more often in the two conditions incorporating an educational manipulation than in the control condition.

Method

\section{Participants}

\section{Chimpanzee Residents and the Zoo}

Data collection occurred at the former Zoo Northwest Florida, located in Gulf Breeze, Florida in the United States. The zoo spanned 202,343 $\mathrm{m}^{2}$ and was home to 900 animals, including several species of nonhuman primates. One of the main attractions of the zoo was the 121,406 $\mathrm{m}^{2}$ Gorilla Island Wildlife Preserve, which housed the chimpanzee and gorilla exhibits as well as many free-ranging ungulate and avian species. There were two adult chimpanzees (Pan troglodytes) living at the zoo at the time of data collection.

\section{Visitor Platform}

A wooden boardwalk above the wildlife preserve extended from the edge of the preserve to its center. A platform was at the end of the boardwalk, and visitors on the platform could view both the chimpanzee and gorilla exhibits and a large portion of the preserve. On the platform were two coinoperated telescopes, a wooden gorilla sculpture, and several signs describing chimpanzees, gorillas, and other species. The front portion was an area on the platform within $1 \mathrm{~m}$ of the front railing closest to the chimpanzee island. The chimpanzees could see visitors on the platform, particularly visitors in the front portion.

\section{Procedure}

\section{Visitor Conditions}

There were three conditions of visitor education. The sign condition was the presence of a graphic sign on the visitor platform that illustrated and described affinitive chimpanzee behaviors specifically play faces, play slaps, and head nods. The sign was mounted on the platform railing. The design of the graphic sign is presented in Figure 1. The docent condition was the presence of a trained docent on the visitor platform. Prior to data collection, the investigator trained docents to understand chimpanzee behaviors, using written materials, illustrations, and demonstration. Docents learned basic chimpanzee behavioral contexts. They learned to identify affinitive and aggressive chimpanzee behaviors. During the docent condition, the docent described affinitive chimpanzee behaviors including play faces, play slaps, and head nods to each group of visitors who approached on the platform. The docent encouraged visitors to use these specific behaviors. The docent also answered visitor questions and interpreted chimpanzee behaviors, pointing out both friendly and aggressive behaviors that appeared. In the control condition, the sign and docent were absent and there was no other interpretive material present. 
Figure 1

Design of the Graphic Sign Posted on the Railing of the Visitor Platform During the Sign Condition

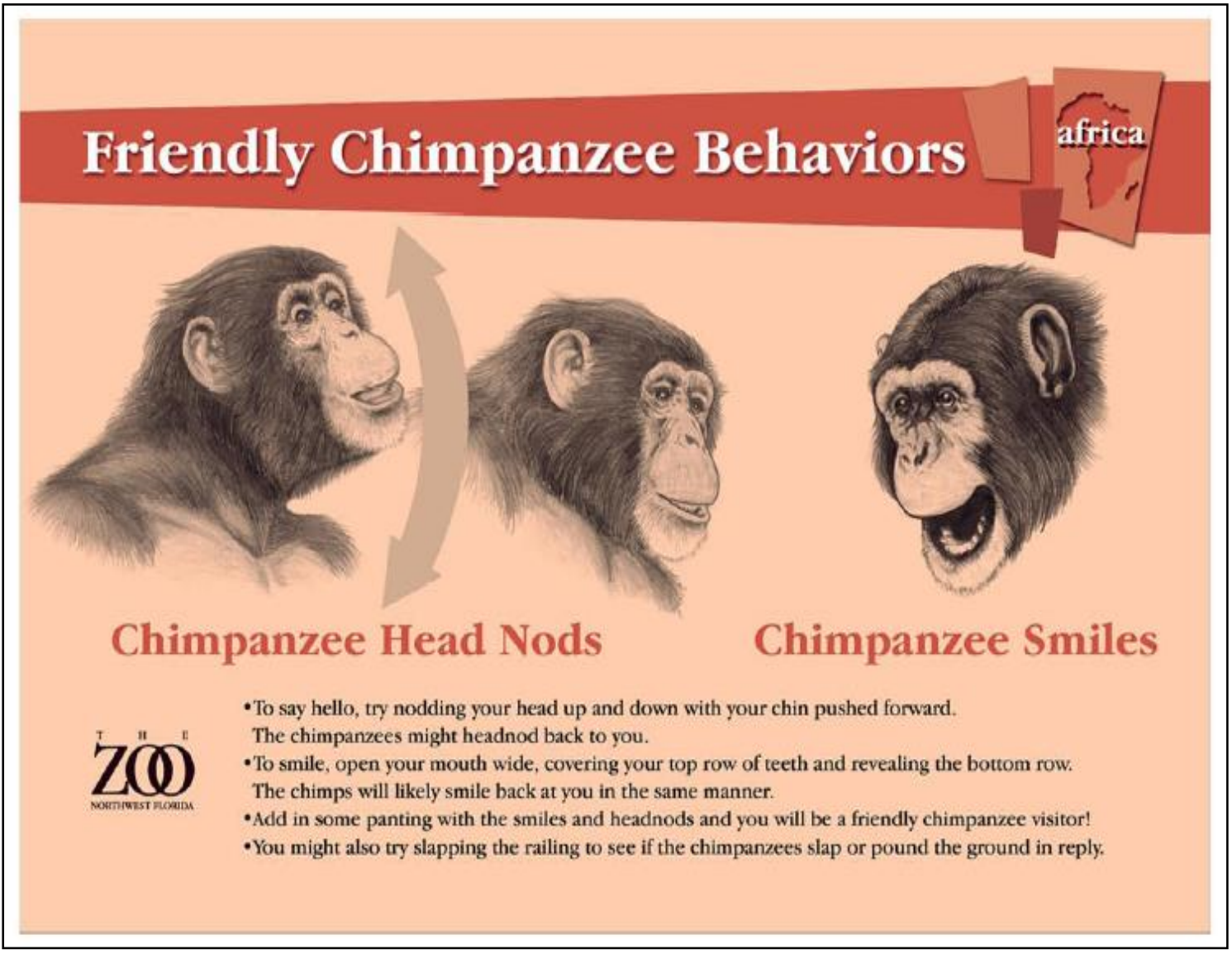

\section{Data Collection Schedule}

Wireless video cameras recorded the behavior of visitors to the platform between 10:00 a.m. and 4:00 p.m. on 16 nonconsecutive days between June 16 and July 8, 2009. The zoo was located in a summer vacation destination area so all days of the week had equal attendance in June and July. Data collection was divided into 2-hr time blocks: 10:00 a.m. to 12:00 p.m., 12:00 p.m. to 2:00 p.m., or 2:00 p.m. to 4:00 p.m. and a single condition appeared in each block. All three conditions were presented on each day of data collection. For example, Monday may have docent 10:00 a.m. to 12:00 p.m., sign 12:00 p.m. to 2:00 p.m. and control 2:00 p.m. to 4:00 p.m. Tuesday may have control 10:00 a.m. to 12:00 p.m., sign 12:00 p.m. to 2:00 p.m. and docent 2:00 p.m. to 4:00 p.m. The order of the presentation of conditions were randomized without replacement to ensure each condition was balanced for time. Each condition was presented 16 times for a total of 48 2-hr time blocks or $96 \mathrm{hrs}$.

\section{Data Selection for Visitor Location}

An initial analysis determined when visitors were present in the front portion of the platform, which was the viewing area closest to the chimpanzee island, to ensure visitors were viewing the chimpanzees. Only times in which one or more visitors occupied the front portion of the platform were selected and included in subsequent data analyses. 


\section{Visitor Behavior Coding}

For the selected data, researchers used a 1/0 sampling method (Altmann, 1974; Smith, 1985) scoring every $5 \mathrm{~s}$ interval the behaviors of the visitors. During each interval, researchers recorded whether or not each behavior in the study ethogram occurred. Behaviors recorded were wave, extension of hand or arm (which included throwing an object), hand clap, play slap, hit railing, head nod, climb railing, run, jump, and look at sign. These behaviors are defined in Table 1. Play face was not included because it was difficult to reliably and consistently observe visitor faces on the videotapes. At times, visitors faced away from the camera. There was no count of visitors or indication of visitor density in this analysis.

Table 1

Ethogram of Visitor Behaviors

\begin{tabular}{ll}
\hline Behavior & Definition \\
\hline Wave & Visitor extends arm away from body and moves hand side to side or up and down \\
Hand/arm extension & Visitor extends arm away from body in any direction and hand (in any configuration) may or may \\
not move \\
Visitor brings hands together quickly one or more times \\
Play slap & Visitor hits railing with open palm one or more times \\
Hit railing & Visitor touches railing forcibly with closed fist or object \\
Head nod & Visitor moves head up and down repeatedly \\
Climb railing & Visitor climbs, stands, or sits on railing of platform \\
Run & Visitor locomotes rapidly \\
Jump & Visitor brings both feet off the ground simultaneously \\
Look at sign & Visitor looks in the direction of the graphic sign for $3 \mathrm{~s}$ or more \\
\hline
\end{tabular}

\section{Visitor Activity Level Coding}

Researchers classified each $5 \mathrm{~s}$ interval as active when one or more visitors engaged in any behavior in the ethogram. Researchers classified each $5 \mathrm{~s}$ interval as passive when no visitor engaged in a behavior in the ethogram.

\section{Interobserver Reliability}

Four researchers independently coded portions of the data. Prior to independent coding, data each data collector coded a $20 \%$ of the data with a second reliable observer. Interobserver agreement between a coder and the first coder was calculated. Each coder scored between 85-89\%. Data coders coded the same $20 \%$ of the data and obtained agreement ranging from $85-89 \%$.

\section{“Look at Sign” Coding}

For each interval that contained the code for "Look at sign", we recorded duration in s of each look. We then coded the presence/absence of head nods in the subsequent $10 \mathrm{~s}$. Interobserver agreement was $86.7 \%$ for this analysis.

Prior to data collection, the study received approval from Central Washington University Institutional Review Boards for human and animal subject protections (H08121). 


\section{Results}

Visitors were present in the front portion of the visitor platform for $31 \mathrm{hr} 7 \mathrm{~min} 25 \mathrm{~s}$, which was the data selected for analysis. There were 7,091 intervals in the control, 7,531 intervals in the docent, and 7,787 in the sign in which visitor were present in the front of the platform. The following results are from this selection of intervals

\section{Active vs. Passive Visitors}

A $3 \times 2$ chi-square showed there were significant differences in the distribution of intervals with active versus passive visitors between three visitor conditions $\chi^{2}(2, N=22,409)=61.98, p<.001$. To determine how cells within these chi-squares individually contributed to the overall significance of each result, the standardized residual (SR) of each cell was examined as a $z$-score (Haberman, 1973). Vasserstats.net (Lowry, 2021) calculated chi-squares, expected scores, and standardized residuals. Visitors were significantly more active in the sign condition than expected given the null hypothesis, SR $=4.48, p<.001$. Visitors were significantly less active in the docent condition than expected given the null hypothesis, $\mathrm{SR}=-4.51, p<.001$. Table 2 shows the percent of intervals within each category and condition. Figure 2 shows the number of expected and observed intervals of visitor behavior categories as they varied by experimental condition. Note the control condition had observed values that were not significantly different than expected values.

Table 2

Percent of Intervals Containing Active Versus Passive Visitor Behavior

\begin{tabular}{lccc}
\hline Interval Class & Control & Docent & Sign \\
\hline Active & 11.0 & 10.7 & 13.1 \\
Passive & 20.6 & 23.0 & 22.7 \\
\hline
\end{tabular}

\section{Play Slaps and Head Nods}

We compared the number of intervals containing play slaps and head nods between each condition as these behaviors were the affinitive behaviors encouraged in both experimental conditions. Table 3 shows the percent of intervals that play slap and head nods were present and absent. The behaviors were relatively rare; head nod was the most prevalent in only $2.2 \%$ of the intervals. Nonetheless, a $1 \times 3$ chi-square showed there was a significant difference between conditions in the number of intervals with head nods present $\chi^{2}(2, N=764)=406.64, p<.0001$. Visitors were significantly more likely to head nod in the docent condition than expected given the null hypothesis, $\mathrm{SR}=14.81, p<$ .001. Visitors were less likely to head nod in the control condition than expected given the null hypothesis, $\mathrm{SR}=-13.96, p<.001$. Head nods in the sign condition were close to the expected value $\mathrm{SR}=$ $0.73, p>.01$. Figure 3 displays the number of expected and observed intervals of visitors' head nod behavior across experimental conditions. Expected values were calculated from the expected proportion of intervals in each condition.

Play slaps were most prevalent in the docent condition, although they only appeared in $0.1 \%$ of all intervals. Table 3 shows the percent of intervals in which a play slap appeared. A $1 \times 3$ chi-square showed significant differences in the number of intervals containing play slaps between conditions $\chi^{2}(2$, $N=157)=141.31, p<.0001$. Visitors were significantly more likely to engage in play slaps in the sign condition than expected given the null hypothesis, $\mathrm{SR}=9.39, p<.001$. Visitors were less likely to play slap in the control, $\mathrm{SR}=-5.11 p<.001$ and docent $\mathrm{SR}=-4.3 p<.001$ conditions than expected. Figure 3 displays the number of expected and observed intervals of visitors' play slap behavior across conditions. Expected values were calculated from the expected proportion of intervals in each condition. 
Figure 2

Active and Passive Behavior Across Visitor Conditions

Active Behavior

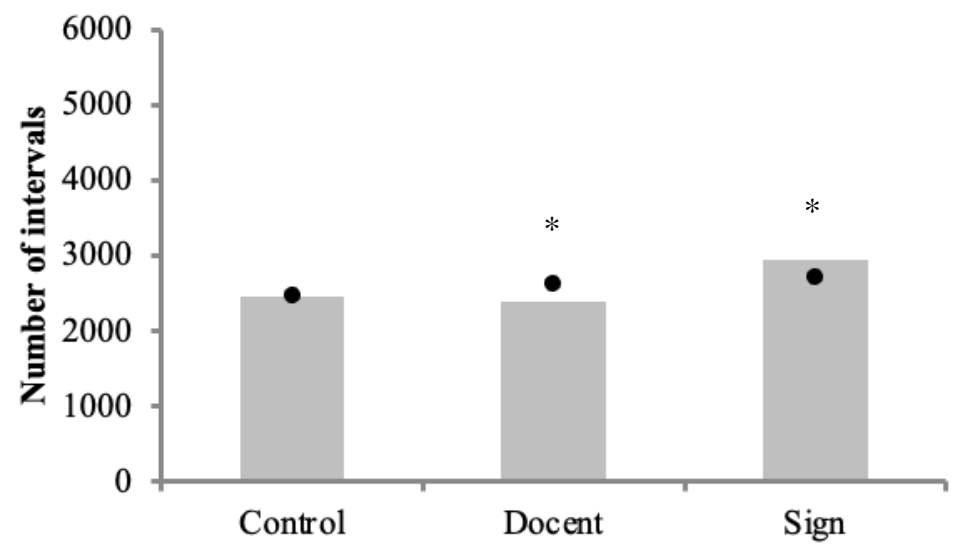

Passive Behavior

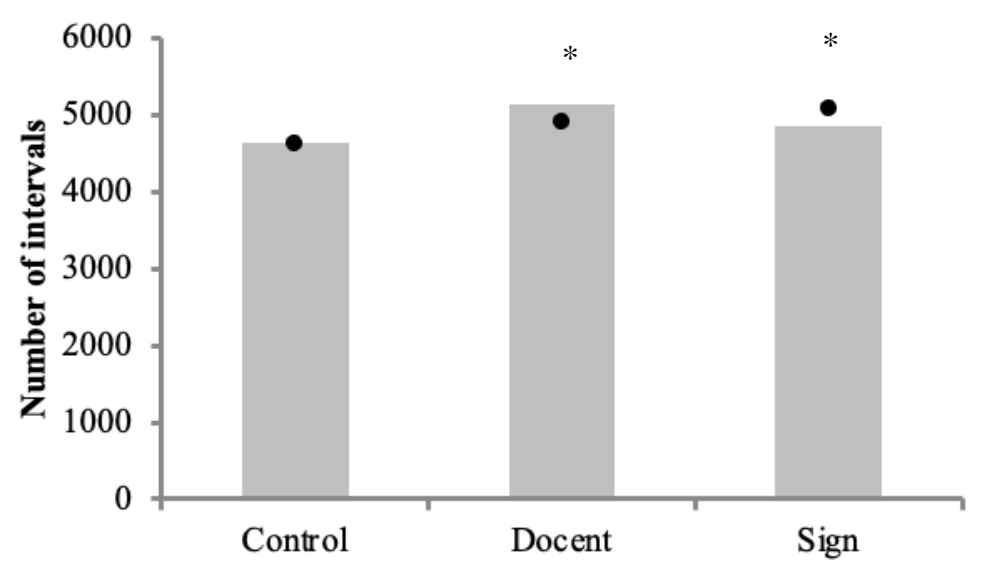

Note: Bars represent observed frequencies of active and passive intervals, circles $(\bullet)$ represent expected frequencies of intervals. Expected values were based on the proportion of intervals in each condition. ${ }^{*} p<.001$

\section{Table 3}

Percent of Intervals Containing Affinitive Visitor Behaviors

\begin{tabular}{cccc}
\hline Behavior & Control & Docent & Sign \\
\hline Head nod & & & 1.1 \\
Present & 0.1 & 2.2 & 33.6 \\
Absent & 31.5 & 31.4 & \\
Play slap & & & 0.5 \\
Present & 0.06 & 0.1 & 34.2 \\
Absent & 31.6 & 33.6 & \\
\hline
\end{tabular}


Figure 3

Presence of Head Nod and Play Slap Behavior
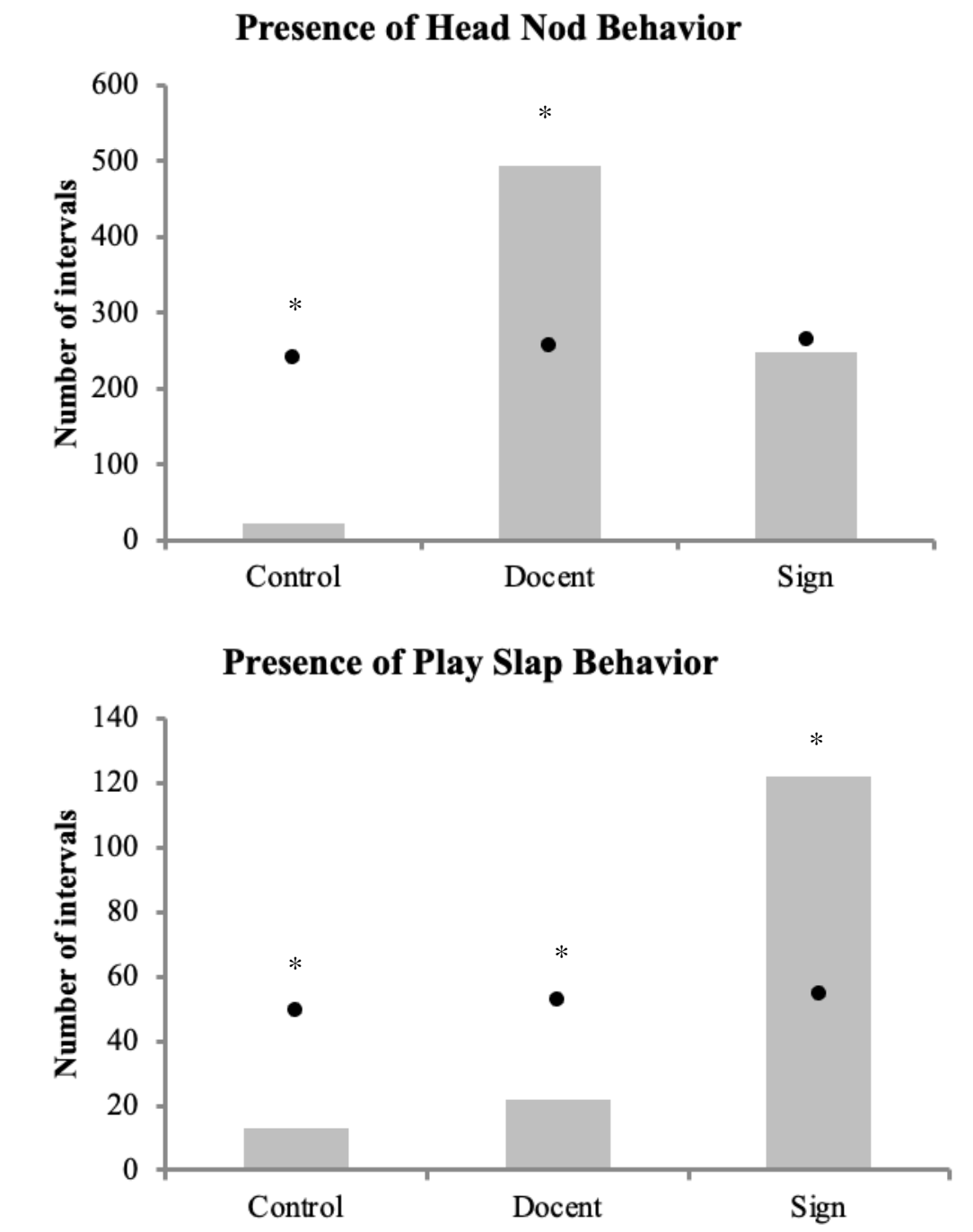

Note: Bars represent observed frequencies of head nod and play slap behaviors, respectively. Circles $(\bullet)$ represent expected frequencies of head nod and play slap behaviors, respectively. ${ }^{*} p<.001$

\section{"Look at Sign"}

Visitors looked at the sign in only $2.7 \%$ of intervals during the sign condition. There were 96 "look at sign" behaviors in the sign condition. Of those "look at sign" behaviors, 36 (37.5\%) were followed by head nods in the subsequent $10 \mathrm{~s}$. "Look at sign"s followed by head nods lasted a mean of $13.14 \mathrm{~s}$ and a range of 3-54 s. Finally, "look at sign"s followed by an absence of head nods lasted a mean of $11.02 \mathrm{~s}$ and a range of 2-67 s.

\section{Discussion}

Visitors were more likely to play slap or head nod during the docent and sign conditions than the control condition, but these behaviors remained low overall. These results suggest that the docent and the sign have the potential to be effective interventions as their presence or absence significantly affected specific aspects of visitor behavior. The graphic sign depicted an illustration of a head nod and textually 
referred to the play slap as a means of initiating an interaction with the chimpanzees. Consequently, visitors were more likely to play slap in the sign condition than in the docent or control conditions. Play slap was coded differently than hit railing; thus, the manipulation increased a species-typical chimpanzee behavior. In contrast to the graphic sign, the docent did not encourage the use of play slaps and instead encouraged the use of the head nod. As a result, visitors were more likely to head nod in the docent condition than in the sign or control conditions.

Both play slaps and head nods are affinitive behaviors in chimpanzee communities (Goodall, 1986). Head nods are used by all chimpanzee group members to initiate affiliative interactions. Play slaps are gestures used both to initiate and prolong play sequences between chimpanzees. These behaviors lead to additional affiliation and facilitate positive relationships. Similarly, the use of the head nod and play slap by zoo visitors may also serve to increase affinitive interactions between human visitors and chimpanzee residents.

Visitors engaged in less active behavior than expected in the docent condition and engaged in more active behavior during the sign condition than the control condition. The lower levels of visitor activity during the docent condition could be because visitors were listening to the docent. Interactions such as interpretive presentations and keeper talks increases visitor learning and comprehension (Lindemann-Matthies \& Kamer, 2005; Perdue et al., 2012). Visitors who engage in these interpretive interactions tend to spend more time at zoo exhibits (Perdue et al., 2012; Ross \& Gillespie, 2009) and find their zoo experience more memorable (Patterson \& Bitgood, 1988). Our results are suggestive that interactive interpretive programs can be an effective way to engage visitors, increase learning, and support the mission of zoos. Specifically, clear signage and docents to convey information and interpretation of species behavior may be ways to do this.

Some studies (Choo et al., 2011; Hosey \& Druck, 1987;) found that zoo primates react to active audiences more than passive audiences. Finding ways to make audiences more passive may be a way to decrease the impact of audiences on zoo residents, and our results suggest docents could be an effective means of doing so. Docents can receive training to deliver quality information and this can easily become part of zoo education programming. Information should include natural history and species-typical behaviors. Visitors can be encouraged to look for these behaviors and try to use affinitive ones. Information about husbandry, diet, and enrichment also can be included. Resources to understand chimpanzee behavior are freely available online such as a Chimpanzee Behavioral Taxonomy (Fleury, 2017) and a Caregiver Video (Fauna Foundation, 2021), which show ways humans can incorporate chimpanzee behaviors in interactions. Even though this might cause visitors to engage in more behaviors, we found that the groups were more passive when docents were present. Yet, active audiences potentially could elicit reactions from zoo residents. Perhaps there are qualitative differences in those reactions, affinitive versus aggressive. If visitors are employing only affinitive behavior, rather than potentially aggressive ones such as yelling or swaggering, then active audiences may not be so problematic.

The number of intervals with visitors looking toward the sign was low, suggesting that visitors were unlikely to read the graphic sign. Despite the infrequency, when visitors did look at it, over $30 \%$ of the time they exhibited a suggested behavior: the head nod. Visitors who head nodded looked at the sign an average of $2 \mathrm{~s}$ longer than those who did not head nod. Our results provide minimum support to using signs. Likewise, Bashaw and Maple (2001) found visitors often failed to use a sign to locate a tiger in the exhibit. For many zoos, signs remain the most frequent medium for information (Altman, 1998) and will likely continue to be used because of their ease and relative low cost compared to newer technology. Since signs will likely remain a part of zoo exhibits, it is useful to understand how the public uses them. Signs that use graphics, color, and are posted with high visibility increase visitor interest and prolong the time visitors spend at a particular exhibit (Bitgood et al., 1998; Foster et al., 1988). Signs can discourage visitors from using disruptive behaviors (Dancer \& Burn, 2009; Kratochvil \& Schwammer, 1997). The current study illustrates that signs also can encourage specific behaviors in zoo visitors. Future research could take a deeper look at the role of signs in encouraging specific behaviors.

Ultimately, animals in zoos serve as a means for visitors to connect with the natural world (Rabb \& Saunders, 2005). In the current climate of endangered species, habitat loss, and destruction of natural 
resources, zoos now must shift from institutions promoting environmental knowledge to institutions facilitating positive relationships between humans and nature (Ogden \& Heimlich, 2009; Vining, 2003). In this regard, interactive educational programs, specifically those that emphasize the use of speciesspecific, affinitive behavior by zoo visitors can be a powerful tool to fulfill both the educational and conservational missions of zoos.

\section{Acknowledgements}

This research was supported by the Animal Welfare Institute and Lamar Corporation. We would like to thank staff at The Zoo Northwest Florida, interns at the Chimpanzee \& Human Communication Institute, and anonymous peer reviewers.

Conflict of Interest Statement: We have no conflict of interest to report.

\section{References}

Altmann, J. (1974). Observational study of behavior: Sampling methods. Behaviour, 49(3-4), $227-266$.

Altman, J. D. (1998). Animal activity and visitor learning at the zoo. Anthrözoos, 11(1), 12-21.

Ballantyne, R., \& Packer, J. (2016). Visitors' perceptions of the conservation education role of zoos and aquariums: Implications for the provision of learning experiences. Visitor Studies, 19(2), 193-210.

Bashaw, M. J., \& Maple, T. L. (2001). Signs fail to increase zoo visitors' ability to see tigers. Curator: The Museum Journal, 44(3), 297-304.

Birke, L. (2002). Effects of browse, human visitors and noise on the behaviour of captive orangutans. Animal Welfare, 11, 189-202.

Birney, B. A. (1988). Criteria for successful museum and zoo visits: Children offer guidance. Curator, 31(4), 292316.

Bitgood, S., Carnes, J., Nabors, A., \& Patterson, D. (1988). Controlling public feeding of zoo animals. Visitor Behavior, 2(4), 6.

Bitgood, S., Patterson, D., Benefield, A., \& Landers, A. (1986). Understanding your visitors: Ten factors that influence their behavior (Report No. 86-60). Center for Social Design.

Boyle, S. A., Berry, N., Cayton, J., Ferguson, S., Gilgan, A., Khan, A., Lam, H., Leavelle, S., Mulder, I., Myers, R., Owens, A., Park, J., Siddiq, I., Sleven, M., Weidow, T., Yu, A., \& Reichling, S. (2020). Widespread behavioral responses by mammals and fish to zoo visitors highlight differences between individual animals. Animals, 10(11), 2108.

Carder, G., \& Semple, S. (2008). Visitor effects on anxiety in two captive groups of western lowland gorillas. Applied Animal Behavioral Science, 115, 211-220.

Carr, N., \& Cohen, S. (2011). The public face of zoos: Images of entertainment, education and conservation. Anthrozoös, 24(2), 175-189.

Carter, M., Webber, S., Rawson, S., Smith, W., Purdam, J., \& McLeod, E. (2020). Virtual reality in the zoo: A qualitative evaluation of a stereoscopic virtual reality video encounter with little penguins (Eudyptula minor). Journal of Zoo and Aquarium Research, 8(4), 239-245.

Chamove, A., Hosey, G., \& Schaetzel, P. (1988). Visitors excite primates in zoos. Zoo Biology, 7, 359-369.

Chiew, S. J., Butler, K. L., Sherwen, S. L., Coleman, G. J., Fanson, K. V., \& Hemsworth, P. H. (2019). Effects of regulating visitor viewing proximity and the intensity of visitor behaviour on little penguin (Eudyptula minor) behaviour and welfare. Animals, 9(6), 285.

Choo, Y., Todd, P. A., \& Li, D. (2011). Visitor effects on zoo orangutans in two novel, naturalistic enclosures. Applied Animal Behaviour Science, 133(1-2), 78-86.

Claxton, A. M. (2011). The potential of the human-animal relationship as an environmental enrichment for the welfare of zoo-housed animals. Applied Animal Behaviour Science, 133(1-2), 1-10.

Coe, J. C. (1992). Bringing it all together: Integration of context, content and message in zoo exhibit design. $A A Z P A$ Annual Proceedings, 268-274.

Cook, S., \& Hosey, G. R. (1995). Interaction sequences between chimpanzees and human visitors at the zoo. Zoo Biology, 14(5), 431-440. 
D’Cruze, N., Khan, S., Carder, G., Megson, D., Coulthard, E., Norrey, J., \& Groves, G. (2019). A global review of animal-visitor interactions in modern zoos and aquariums and their implications for wild animal welfare. Animals, 9(6), 332.

Dancer, A. M., \& Burn, C. C. (2019). Visitor effects on zoo-housed Sulawesi crested macaque (Macaca nigra) behaviour: Can signs with 'watching eyes' requesting quietness help? Applied Animal Behaviour Science, 211, 88-94.

Davey, G. (2006). Visitor behavior in zoos: A review. Anthrözoos, 19(2), 143-157.

Davey, G. (2007). Visitors' effects on the welfare of animals in the zoo: A review. Journal of Applied Animal Welfare Science, 10(2), 169-183.

Falk, J. H., Reinhard, E. M., Vernon, C. L., Bronnenkant, K., Deans, N. L., \& Heimlich, J. E. (2007). Why zoos and aquariums matter: Assessing the impact of a visit to a zoo or aquarium. Association of Zoos and Aquariums.

Fauna Foundation (February 4, 2021). Caregiver video $2015 . \quad$ [Video]. YouTube. https://www.youtube.com/watch?v=Si9pV2W2L0s.

Fernandez, E. J., Tamborski, M. A., Pickens, S. R., \& Timberlake, W. (2009). Animal-visitor interactions at the modern zoo: Conflicts and interventions. Applied Animal Behaviour Science, 120, 1-8.

Fleury, E. (2017, June 1). Chimpanzee behavioral taxonomy [Video]. YouTube. https://www.youtube.com/watch?v=GMCNvL9gI5Q.

Foster, J. S., Koran, J. J., Koran, M. L., Stark, S., Blackwood, A., \& Landers, H. (1988). The effect of multispecies exhibits on visitor attention at the Jacksonville Zoological Park. In S. Bitgood, J. T. Roper, \& A. Benefield (Eds.), Visitor studies: Theory, research, and practice (pp. 113-117). Center for Social Design.

Godinez, A. M., \& Fernandez, E. J. (2019). What is the zoo experience? How zoos impact a visitor's behaviors, perceptions, and conservation efforts. Frontiers in Psychology, 10, 1746.

Gold, K., \& Beneviste, P. (1995). Visitor behavior and attitudes toward great apes at Lincoln Park Zoo. American Zoo and Aquarium Association Annual Conference Proceedings, 152-158.

Goodall, J. (1986). The chimpanzees of Gombe: Patterns of behavior. The Belknap Press of Harvard University Press.

Haberman, S. J. (1973). The analysis of residuals in cross-classified tables. Biometrics, 29(1), $205-220$.

Hosey, G. R., \& Druck, P. L. (1987). The influence of zoo visitors on the behaviour of captive primates. Applied Animal Behaviour Science, 18(1), 19-29.

Hosey, G., \& Melfi, V. (2015). Are we ignoring neutral and negative human-animal relationships in zoos? Zoo Biology, 34(1), 1-8.

Hutchins, M., \& Smith, B. (2003). Characteristics of a world-class zoo or aquarium in the 21 st century. International Zoo Yearbook, 38, 130-141.

Jensvold, M. L. (2008). Chimpanzee (Pan troglodytes) responses to caregiver use of chimpanzee behaviors. Zoo Biology, 27, 345-359.

Kratochvil, H., \& Schwammer, H. (1997). Reducing acoustic disturbances by aquarium visitors. Zoo Biology, 16, 349-353.

Kreger, M. D., \& Mench, J. A. (1995). Visitor-animal interactions at the zoo. Anthrozoös, 8(3), $143-158$.

Kuhar, C. (2008). Group differences in captive gorillas' reaction to large crowds. Applied Animal Behaviour Science, 110, 377-385.

Lee, H. S. (2015). Measurement of visitors' satisfaction with public zoos in Korea using importance-performance analysis. Tourism Management, 47, 251-260.

Lindemann-Matthies, P., \& Kamer, T. (2005). The influence of an interactive educational approach on visitors' learning in a Swiss zoo. Science Education, 90, 296-315.

Lowry, R. (2021). Vassar stats: Website for statistical computation www.vassarstats.net

Luebke, J. F., Watters, J. V., Packer, J., Miller, L. J., \& Powell, D. M. (2016). Zoo visitors' affective responses to observing animal behaviors. Visitor Studies, 19(1), 60-76.

Mallapur, A., Sinha, A., \& Waran, N. (2005). Influence of visitor presence on the behavior of captive lion-tailed macaques (Macaca silenus) housed in Indian zoos. Applied Animal Behavioral Science, 94, 341-352.

Margulis, S. W., Hoyos, C., \& Anderson, M. (2003). Effect of felid activity on zoo visitor interest. Zoo Biology, 22(6), 587-599.

Mench, J., \& Kreger, J. (1995). Animal welfare and public perceptions associated with keeping wild animals in captivity. American Zoo and Aquarium Association Annual Conference Proceedings, 376-383.

Milan, L. M., \& Wourms, M. K. (1993). The world of birds at the Bronx Zoo/Wildlife Conservation Park: Visitor expectations and experiences. International Zoo Yearbook, 32, 204-212. 
Mitchell, G., Herring, F., \& Obradovich, S. (1992). Like threaten like in mangabeys and people? Anthrözoos, 5(2), $106-112$.

Morgan, J. M., \& Hodgkinson, M. (1999). The motivation and social orientation of visitors attending a contemporary zoological park. Environment and Behavior, 31(2), 227-239.

Nimon, A., \& Dalziel F. (1992). Cross-species interaction and communication: A study method applied to captive siamang (Hylobates syndactylus) and long-billed corella (Cacatua tenuirostris) contacts with humans. Applied Animal Behavioral Science, 33, 261-272.

Ogden, J., \& Heimlich, J. E. (2009). Why focus on zoo and aquarium education? Zoo Biology, 28, 357-360.

Osvath, M. (2009). Spontaneous planning for future stone throwing by a male chimpanzee. Current Biology, 19(5), R190-R191.

Patterson, D., \& Bitgood, S. (1988). Some evolving principles of visitor behavior. In S. Bitgood, J. T. Roper, \& A. Benefield (Eds.), Visitor studies: Theory, research, and practice (pp. 40-50). Center for Social Design.

Perdue, B. M., Stoinski, T. S., \& Maple, T. L. (2012). Using technology to educate zoo visitors about conservation. Visitor Studies, 15(1), 16-27.

Rabb, G. B. (2004). The evolution of zoos from menageries to centers of conservation and caring. Curator, 47(3), 237-246.

Rabb, G. B., \& Saunders, C. D. (2005). The future of zoos and aquariums: Conservation and caring. International Zoo Yearbook, 39, 1-26.

Reade, L. S., \& Waran, N. K. (1996). The modern zoo: How do people perceive zoo animals? Applied Animal Behaviour Science, 47, 109-118.

Ross, S. R., \& Gillespie, K. L. (2009). Influences on visitor behavior at a modern immersive zoo exhibit. Zoo Biology, 28, 462-472.

Ross, S. R., \& Lukas, K. E. (2005). Zoo visitor behavior at an African ape exhibit. Visitor Studies Today, 8(1), 4-12.

Sherwen, S. L., \& Hemsworth, P. H. (2019). The visitor effect on zoo animals: Implications and opportunities for zoo animal welfare. Animals, 9(6), 366.

Smith, P. K. (1985). The reliability and validity of one-zero sampling: Misconceived criticisms and unacknowledged assumptions. British Educational Research Journal, 11(3), 215-220.

Smith, L., Broad, S., \& Weiler, B. (2008). A closer examination of the impact of zoo visits on visitor behaviour. Journal of Sustainable Tourism, 16(5), 544-562.

Stoinski, T. S., Jaicks, H. F., \& Drayton, L. A. (2012). Visitor effects on the behavior of captive western lowland gorillas: The importance of individual differences in examining welfare. Zoo Biology, 31(5), 586-599.

Stoinski, T. S., Ogden, J. J., Gold, K. C., \& Maple, T. L. (2001). Captive apes and zoo education. In B. B. Beck, T. S. Stoinski, M. Hutchings, T. L. Maple, \& B. Norton (Eds.), Great apes and humans: The ethics of coexistence (pp.113-132). Smithsonian Institution Press.

Wells, D. L. (2005). A note on the influence of visitors on the behavior and welfare of zoo-housed gorillas. Applied Animal Behavioral Science, 3, 13-17.

Vining, J. (2003). The connection to other animals and caring for nature. Human Ecology Review, 10(2), 87-99.

Webber, S., Carter, M., Sherwen, S., Smith, W., Joukhadar, Z., \& Vetere, F. (2017, May). Kinecting with orangutans: Zoo visitors' empathetic responses to animals' use of interactive technology. In Proceedings of the 2017 CHI Conference on Human Factors in Computing Systems, pp. 6075-6088.

Webber, S., Carter, M., Smith, W., \& Vetere, F. (2017). Interactive technology and human-animal encounters at the zoo. International Journal of Human-Computer Studies, 98, 150-168.

Wood, W. (1998). Interactions among environmental enrichment, viewing crowds, and zoo chimpanzees (Pan troglodytes). Zoo Biology, 17(3), 211-230. 